\title{
Diversity in Unity: A Face off with Health Sector of BRICS Nations
}

\author{
Uma \\ Department of Economics, Lakshmibai College, University of Delhi INDIA \\ *Correspondence: umalbc@lb.du.ac.in
}

\begin{abstract}
The thirteenth summit of BRICS nations was held recently under the chairmanship of India on 9th September 2021. No doubt it was a moment of pride which needs to be celebrated on political front, as all the five BRICS nations reiterated their commitment of enhancing intra-BRICS cooperation under the three pillars - political and security, economic and financial, and cultural \& people-to-people exchanges, but have we got holistic pride as well? No, as we are far behind from three nations of BRICS; Federation of Russia, China and Brazil if we look at our health sector. A pertinent question arises why we lack compatibility with BRICS nations in health sector? If we look at the period from 2005 to 2019 the current health expenditure (per cent of GDP) is well below in India in comparison to other BRICS nations. The low expenditure affects the health-related amenities in terms of availability of beds, physicians, nurses and mid-wives etc. Thus, it puts pressure on the general public to spend more on health. This in turn increases out-of-pocket expenditure of poor citizens. The paper tries to examine the expenditure incurred by BRICS nations on health sector and find out the health services such as; availability of beds, physicians, nurses and mid-wives etc. It also examines the relationship between health expenditure and out of -pocket expenditure. The study will try to evaluate how healthy are the citizens of BRICS nations on the basis of few selected indicators related to physical health. It will look at the pertinent question; where India stands amongst all the nations of BRICS? In the concluding part policy aspects will be discussed so that each member nation can improve in the areas where it lacks so that overall health of the citizens of BRICS nations can go up. This will not only strengthen the bond amongst these nations but also make them prosper more as healthy human resource is the backbone of any nation.
\end{abstract}

KEYWORDS: BRICS, health expenditure, health services, out-of-pocket expenditure, physical health

\section{INTRODUCTION}

The thirteenth summit of BRICS nations was held recently under the chairmanship of India on 9th September 2021. No doubt it was a moment of pride which needs to be celebrated on political front, as all the five BRICS nations reiterated their commitment of enhancing intra-BRICS cooperation under the three pillars - political and security, economic and financial, and cultural \& people-to-people exchanges, but have we got holistic pride as well? No, as we are far behind from three nations of BRICS; Federation of Russia, China and Brazil if we look at our health sector. A pertinent question arises why we lack compatibility with BRICS nations in health sector? If we look at the period from 2005 to 2019 the current health expenditure (per cent of GDP) is well below in India in comparison to other
BRICS nations. The low expenditure affects the healthrelated amenities in terms of availability of beds, physicians, nurses and mid-wives etc. Thus, it puts pressure on the general public to spend more on health. This in turn increases out-of-pocket expenditure of poor citizens. The paper tries to examine the expenditure incurred by BRICS nations on health sector and find out the health services such as; availability of beds, physicians, nurses and mid-wives etc. It also examines the relationship between health expenditure and out of -pocket expenditure. The study will try to evaluate how healthy are the citizens of BRICS nations on the basis of few selected indicators related to physical health. It will look at the pertinent question; where India stands amongst all the nations of BRICS? In the concluding part policy aspects will be discussed so that each member 
nation can improve in the areas where it lacks so that overall health of the citizens of BRICS nations can go up. This will not only strengthen the bond amongst these nations but also make them prosper more as healthy human resource is the backbone of any nation.

Since the late 1980s, BRICS nations; Brazil, Russia, India, China, and South Africa are experiencing a rapid economic growth which is why they are also called as a 'group of emerging economies. In the beginning it was BRIC as firstly used by J. O'Neil in 2001 in his paper. After joining of South Africa in 2010 it became BRICS. The main purpose of formation of BRICS was cooperation at bilateral, trilateral and multilateral levels on various fronts such as finance, investment, security, health and education, trade and cultural exchange. With more than 4 decades of continuous economic growth, China has emerged as an overachieving nation amongst all the BRICS nations on several fronts, be it lifting the poverty, attaining higher growth rate or achieving milestones in improving the health sector.

\section{OBJECTIVES}

- To know the health expenditure of BRICS and find out the health services such as availability of beds, physicians, nurses and mid-wives etc.

- To examine the current health expenditure and out of -pocket expenditure in BRICS countries.

- To evaluate how healthy are the citizens of BRICS nations.

- To identify India's position amongst all the BRICS nations in terms of health infrastructure and physical health of the citizens.

\section{LITERATURE REVIEW}

Jakovljevic, M. et al., (2019) opine that the rapidly developing nations of Brazil, Russia, India, China, and South Africa (BRICS nations) have a combined economic output that makes BRICS countries the world's major emerging economies. Their growth in gross domestic product (GDP) permits increased investments in health care strategies, social support, and decreases in poverty. Buss, P. M., Ferreira, J. R., \& Hoirisch (2014) believe that there is the need and the opportunity for joint action of the BRICS in terms of the "diplomacy of health" reinforcing the whole process of sustainable development. Romaniuk, P. et al., (2020) write that BRICS countries have been distinguished as one group mainly due to similarities in the level of economic development and the process of economic transformation. However, they also prioritize cooperation in the field of health. Kulkarni, L. (2016) in his study finds a positive relation between health outcome and the GDP Per capita, Adult literacy rate, and Out of Pocket expenditure in BRICS countries. The environmental pollution represented by $\mathrm{CO} 2$ emissions per capita metric ton and Female workforce participation rate shows a negative relation with health outcomes. The public health expenditure is showing a positive elasticity with IMR. This implies that higher public expenditure indicates higher IMR or lower health outcomes. Jakovljevic, M. (2017) forecasted the health expenditure landscape of the BRICS nations and projected that up to 2025 China will achieve highest excess growth rate of $2 \%$ and increase its GDP\% spent on health care from $5.4 \%$ in 2012 to $6.6 \%$ in 2025 . Russia's spending will remain highest among BRICS in absolute per capita terms reaching net gain from $\$ 1523$ PPP in 2012 to \$2214 PPP in 2025. Silva Junior, J. B. D. (2014) find that over the past few decades, the BRICS countries (Brazil, the Russian Federation, India, China and South Africa) have occupied a unique position in the world and in the international health community. These countries have made remarkable progress in moving towards universal health coverage and in strengthening their health systems. But they also feel that reaching real consensus on implementation and delivering concrete results will be the key challenge before BRICS nations in the process of improving the health and well-being of millions of people. Larionova, M. (2014) believe that health is an indispensable public good. At the national level, it has been manifested in the commitment of the BRICS members of Brazil, Russia, India, China and South Africa to scale up health financing. They further feel that despite successes in fighting infectious diseases and reducing child and maternal mortality, old risks are persisting and new challenges are emerging, resulting from the 2008 global financial crisis. Hisham, S. et al., (2018) opine that BRICS countries are the five important emerging economies of the world. Their article discusses about the healthcare system of these countries and also takes a look at what and where India can improve and learn from the rest in terms of healthcare. Tediosi, F. et al., (2016) in their study demonstrate that most BRICS countries implicitly supported the global movement for Universal health care (UHC), and that they share an active engagement in promoting UHC. However, only Brazil, China and to some extent South Africa, were recognized as proactively pushing UHC in the global agenda. In addition, despite some concerted actions, BRICS countries seem to act more as individual countries rather than as an allied group. Marten, R., et al., (2014) in their analysis reviewed national data and presented a qualitative analysis of efforts to reach Universal Health Coverage in each of the BRICS countries. Rao, K. D. et al., (2014) opine that although national governments have played a prominent role in the reforms, private financing constitutes a major share of health spending in BRICS. There is a reliance on direct expenditures in China and India and a substantial presence of private insurance in Brazil and South Africa. The Brazilian health reforms resulted from a political movement that made health a constitutional right, whereas those in China, India, the Russian Federation and South Africa were an attempt to improve the performance of the public system and reduce inequities in access. Awe, 0. 0. et al., (2021) mapped the scientific perspective and research publications on anaemia in children and adolescents in the BRICS countries. The review of all scientific studies on anaemia in BRICS nations for the past 30 years revealed gaps in research 
collaborations on anaemia between authors in BRICS nations.

\section{METHODOLOGY}

BRICS countries are selected for the present analysis as a suitable group with respect to health mainly due to the fact that they enhance the value of solidarity and humanitarian assistance on various levels. The study compares health system outcomes in the BRICS countries, assesses the trends of their changes and examines the differences amongst the nations. The paper covers dataset of selected indicators describing health expenditure, health infrastructure, availability of physicians and nurses, midwives and population health status, namely: current health expenditure of BRICS nations (\% of GDP), out-of-pocket expenditure in BRICS nations (\% of current health expenditure) hospital beds, physicians, nurses and midwives, prevalence of undernourishment, prevalence of anaemia among pregnant women, prevalence of anaemia among children, prevalence of anaemia among women of reproductive age, prevalence of anaemia among nonpregnant women, prevalence of overweight and prevalence of stunting, height for age in BRICS nations.

Data sources: The World Health Organization and World Bank Database is the primary source of data for the analysis. The data used for the analysis is for five BRICS countries including Brazil, Russian Federation, India, China, and South Africa for 14 years from 2005 to 2019, in few cases till 2020, depending upon the availability of data. This study aims at examining the differences in the health care systems of emerging economies of BRICS based on the time-series data.

Table 1: Current health expenditure of BRICS nations (\% of GDP)

\begin{tabular}{|l|l|l|l|l|l|}
\hline Year & India & $\begin{array}{l}\text { South } \\
\text { Africa }\end{array}$ & China & $\begin{array}{l}\text { Russian } \\
\text { federation }\end{array}$ & Brazil \\
\hline 2005 & 3.791 & 6.706 & 4.142 & 4.767 & 8.044 \\
\hline 2006 & 3.635 & 6.587 & 3.919 & 4.762 & 8.259 \\
\hline 2007 & 3.518 & 6.431 & 3.659 & 4.743 & 8.208 \\
\hline 2008 & 3.515 & 6.546 & 3.877 & 4.899 & 8.016 \\
\hline 2009 & 3.485 & 7.115 & 4.322 & 5.638 & 8.403 \\
\hline 2010 & 3.272 & 7.415 & 4.208 & 4.966 & 7.949 \\
\hline 2011 & 3.246 & 7.497 & 4.326 & 4.790 & 7.788 \\
\hline 2012 & 3.329 & 7.753 & 4.549 & 4.941 & 7.735 \\
\hline 2013 & 3.749 & 7.721 & 4.710 & 5.080 & 7.977 \\
\hline 2014 & 3.620 & 7.930 & 4.773 & 5.180 & 8.396 \\
\hline 2015 & 3.596 & 8.201 & 4.889 & 5.296 & 8.871 \\
\hline 2016 & 3.511 & 8.096 & 4.982 & 5.265 & 9.207 \\
\hline 2017 & 3.535 & 8.113 & 5.151 & 5.344 & 9.469 \\
\hline 2018 & 3.544 & 8.253 & 5.351 & 5.316 & 9.514 \\
\hline
\end{tabular}

Source: World Health Organization Global Health Expenditure database (http://apps.who.int/nha/database). (Author's compilation)

Expenditure in health care varies across BRICS nations. Four of the 5 nations-Brazil, Russia, China, and South Africa-have managed to increase their health care expenditure over time. The data from table 1 shows that in comparison to 2005 in 2018, health care expenditures increased in Brazil, China, South Africa, and Russia but
India's health care spending is almost stagnant during this period. The highest increase in the health expenditure is visible in South Africa, thereafter Russian federation. In the case of China and Brazil it is mostly volatile, although Brazil maintained a highest expenditure since 2005 till 2018 amongst all the BRICS nations (fig.1). In India, the per centage of current health expenditure of GDP is the lowest amongst all the BRICS nations throughout 2005 till 2018.

Figure 1: Current health expenditure of BRICS nations (\% of GDP)

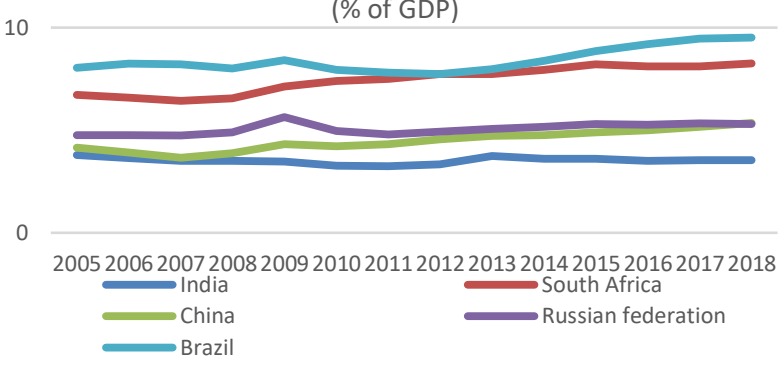

Table 2: Out-of-pocket expenditure in BRICS nations (\% of current health expenditure)

\begin{tabular}{|l|l|l|l|l|l|}
\hline Year & India & $\begin{array}{l}\text { South } \\
\text { Africa }\end{array}$ & China & $\begin{array}{l}\text { Russian } \\
\text { federation }\end{array}$ & Brazil \\
\hline 2005 & 73.149 & 12.355 & 57.690 & 31.932 & 35.876 \\
\hline 2006 & 72.257 & 11.770 & 55.991 & 31.127 & 34.371 \\
\hline 2007 & 70.817 & 11.037 & 51.291 & 31.448 & 33.094 \\
\hline 2008 & 69.148 & 10.139 & 47.368 & 31.549 & 30.884 \\
\hline 2009 & 66.758 & 9.253 & 43.456 & 34.582 & 31.210 \\
\hline 2010 & 65.185 & 8.506 & 40.800 & 35.326 & 29.385 \\
\hline 2011 & 62.225 & 8.399 & 40.266 & 34.194 & 29.300 \\
\hline 2012 & 63.000 & 8.121 & 39.235 & 33.398 & 29.682 \\
\hline 2013 & 69.073 & 8.065 & 38.160 & 34.832 & 28.177 \\
\hline 2014 & 67.014 & 7.905 & 36.565 & 35.826 & 28.180 \\
\hline 2015 & 64.664 & 7.699 & 35.089 & 38.646 & 28.444 \\
\hline 2016 & 63.206 & 7.749 & 35.906 & 40.485 & 27.407 \\
\hline 2017 & 62.401 & 7.767 & 36.050 & 40.493 & 27.455 \\
\hline
\end{tabular}

Source: World Health Organization Global Health Expenditure database (http://apps.who.int/nha/database). (Author's compilation)

Table 2 indicates the Out-of-pocket expenditurei in BRICS nations. The major achievement is fall in out-ofpocket expenditure in all the four nations; India, South Africa, China and Brazil except federation of Russia where it has increased. But still it is highest in India followed by Russia, China and Brazil. In South Africa out of pocket expenditure was lowest in 2005 which occupied the same position even in 2018.

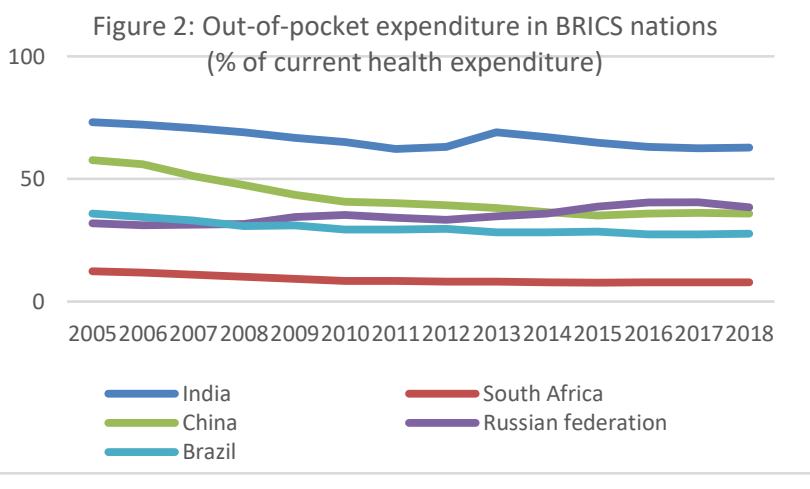


Table 3: Hospital beds in BRICS nations (per 1,000 people)

\begin{tabular}{|l|l|l|l|l|l|}
\hline Year & India & China & $\begin{array}{l}\text { Russian } \\
\text { federation }\end{array}$ & Brazil & $\begin{array}{l}\text { South } \\
\text { Africa }\end{array}$ \\
\hline 2005 & 0.41 & 1.84 & 11.01 & 2.52 & 2.8 \\
\hline 2006 & 0.42 & 1.91 & 10.9 & 2.48 &.. \\
\hline 2007 & 0.41 & 1.99 & 10.71 & 2.47 & 2.41 \\
\hline 2008 & 0.41 & 2.13 & 9.85 & 2.44 & 2.39 \\
\hline 2009 & 0.44 & 2.29 & 9.68 & 2.43 &.. \\
\hline 2010 & 0.47 & 2.47 & 9.41 & 2.37 & 2.3 \\
\hline 2011 & 0.63 & 2.69 & 9.42 & 2.31 &.. \\
\hline 2012 & 0.49 & 3.01 & 9.3 & 2.27 &.. \\
\hline 2013 & 0.49 & 3.29 & 9.07 & 2.25 &.. \\
\hline 2014 & 0.52 & 3.55 & 8.81 & 2.22 &.. \\
\hline 2015 & 0.58 & 3.79 & 8.35 & 2.15 &.. \\
\hline 2016 & 0.48 & 4.02 & 8.16 & 2.11 &.. \\
\hline 2017 & 0.53 & 4.31 & 8.05 & 2.09 &.. \\
\hline 2018 &.. &.. & 7.12 &.. &.. \\
\hline
\end{tabular}

Source: Data are from the World Health Organization, supplemented by country data. (Author's compilation)

In the Table 3 data shows availability of hospital bedsii in BRICS countries. India is having the lowest number of beds per 1,000 people in comparison to all the other BRICS nations. The trend is almost stagnant (fig.3). Although Russia is in the best position but experiencing a decline in the availability of hospital beds since 2005 till 2018, whereas China has shown an increasing trend.

Table 4: Physicians in BRICS nations (per 1,000 people)

\begin{tabular}{|l|l|l|l|l|l|}
\hline Year & India & $\begin{array}{l}\text { South } \\
\text { Africa }\end{array}$ & China & $\begin{array}{l}\text { Russian } \\
\text { federation }\end{array}$ & Brazil \\
\hline 2005 & 0.5758 & 0.6532 & 1.2127 & 2.3204 & 1.6663 \\
\hline 2006 & 0.5852 & 0.6724 & 1.247 & 2.3721 & 1.7007 \\
\hline 2007 & 0.5984 & 0.6988 & 1.2676 & 2.3841 & 1.7306 \\
\hline 2008 & 0.6136 & 0.6968 & 1.3166 & 2.3812 & 1.7802 \\
\hline 2009 & 0.622 & 0.7074 & 1.3922 & 2.3924 & 1.8171 \\
\hline 2010 & 0.6616 & 0.7341 & 1.4532 & 2.393 & 1.8139 \\
\hline 2011 & 0.7376 & 0.7179 & 1.4637 & 6.6305 & 1.8491 \\
\hline 2012 & 0.6982 & 0.7254 & 1.5367 & 4.1303 & 1.8526 \\
\hline 2013 & 0.7182 & 0.7422 & 1.6332 & 4.0705 & 1.882 \\
\hline 2014 & 0.7247 & 0.7541 & 1.6877 & 4.0114 & 1.885 \\
\hline 2015 & 0.745 & 0.7814 & 1.7732 & 3.7494 & 1.932 \\
\hline 2016 & 0.759 & 0.7997 & 1.8647 & 4.0139 & 2.0125 \\
\hline 2017 & 0.7779 & 0.9054 & 1.9798 & 4.2137 & 2.1652 \\
\hline
\end{tabular}

Source: World Health Organization's Global Health Workforce Statistics, OECD, supplemented by country data. (Author's compilation)

Table 4 exhibits the number of Physiciansiii in BRICS nations per 1,000 people. Russia is on top whereas China and Brazil are at par with. India and South Africa are in

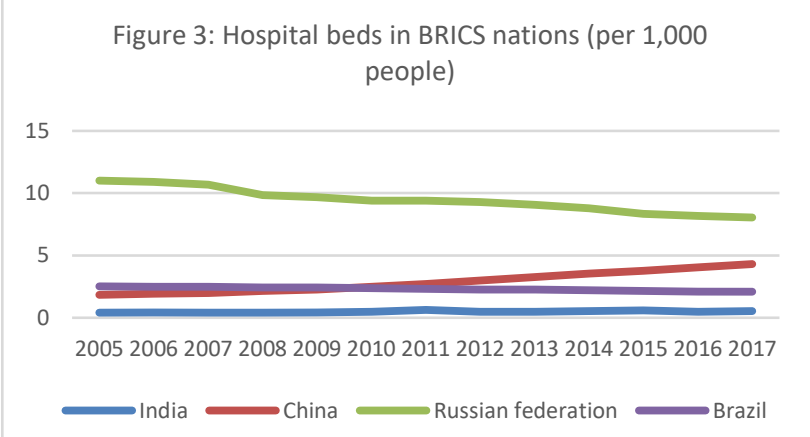

the poorest situation in terms of availability of physicians per 1,000 people.

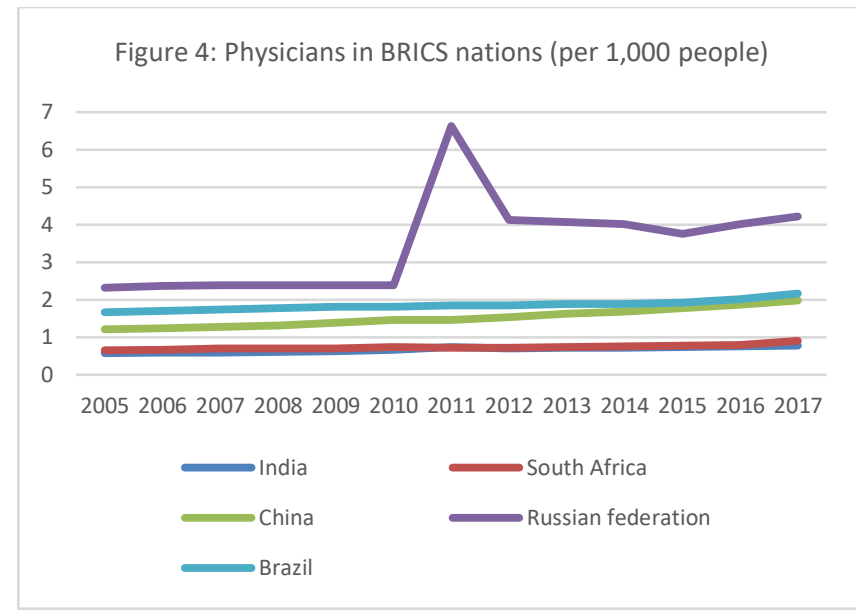

Table 5: Nurses and midwives in BRICS nations (per 1,000 people)

\begin{tabular}{|l|l|l|l|l|l|}
\hline Year & India & $\begin{array}{l}\text { South } \\
\text { Africa }\end{array}$ & China & $\begin{array}{l}\text { Russian } \\
\text { federatio } \\
\text { n }\end{array}$ & Brazil \\
\hline 2005 & 1.2907 & 0.7745 & 1.0086 & 7.7325 & 3.7654 \\
\hline 2006 & 0.7799 & 0.8106 & 1.0599 & 7.8562 & 3.7603 \\
\hline 2007 & 0.7864 & 0.8262 & 1.1518 & 7.8493 & 6.5112 \\
\hline 2008 & 0.8092 & 0.8776 & 1.233 & 7.6953 & 6.4453 \\
\hline 2009 & 0.8568 & 0.9525 & 1.3552 & 7.7276 & 6.544 \\
\hline 2010 & 0.8698 & 1.0225 & 1.4881 & 7.671 & 7.3497 \\
\hline 2011 & 0.9909 & 1.0655 & 1.6213 & 9.1455 & 7.423 \\
\hline 2012 & 1.1108 & 1.1115 & 1.7938 & 4.1443 & 7.521 \\
\hline 2013 & 1.2197 & 1.1881 & 1.9886 & 4.2551 & 7.5635 \\
\hline 2014 & 1.3739 & 1.2264 & 2.1349 & 4.5333 & 8.788 \\
\hline 2015 & 1.4509 & 1.2693 & 2.2914 & 8.9663 & 9.1081 \\
\hline 2016 & 1.4953 & 1.3315 & 2.4665 & 8.5434 & 9.351 \\
\hline 2017 & 2.1079 & 1.3078 & 2.6621 & 8.5429 & 9.737 \\
\hline 2018 & 1.7271 &.. &.. &.. & 10.119 \\
\hline
\end{tabular}

Source: World Health Organization's Global Health Workforce Statistics, OECD, supplemented by country data. (Author's compilation)

Brazil and Russia have the highest number of nurses and midwivesiv per 1,000 people amongst all the BRICS nations. The other three nations; China, South Africa and India are showing a marginal increase in it(fig.5).

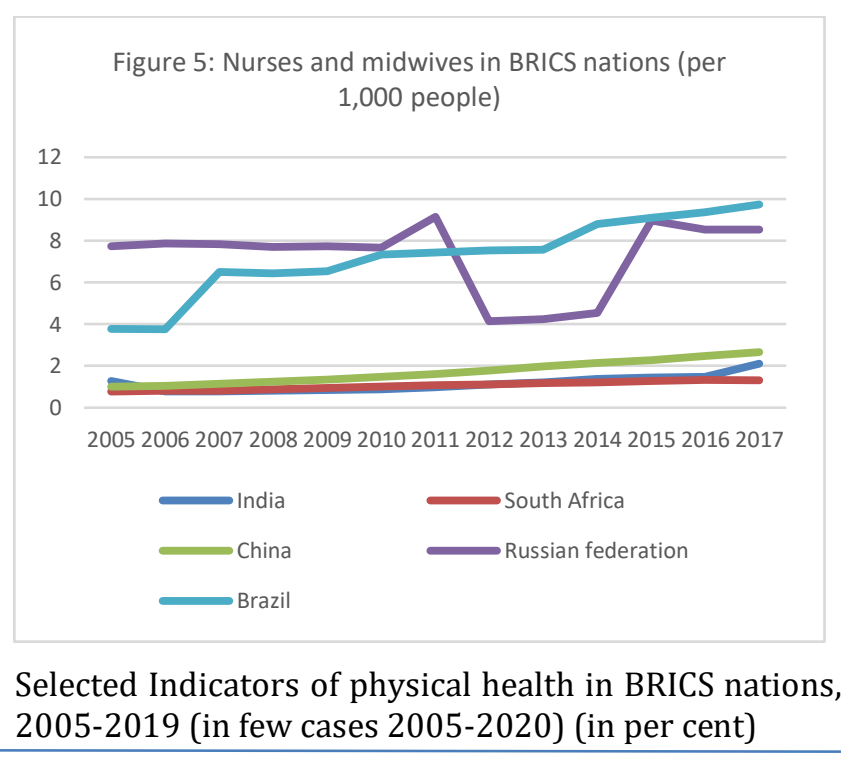

DOI: https://doi.org/10.48001/jbmis.2021.0802001 
Poor current health expenditure, lack of medical doctors, nurses and staffs, a smaller number of available beds in the hospital increases the misery of common people which compels them to search for alternatives for example shifting to private hospital which impacts their pockets. All these constraints affect the overall health of the citizens and ultimately the health of the country.

The below mentioned indicators are studied with trend to show the physical health of the people in BRICS nations.

Table 6: Prevalence of undernourishment $(\%$ of population)

\begin{tabular}{|l|l|l|l|l|l|}
\hline Year & India & $\begin{array}{l}\text { South } \\
\text { Africa }\end{array}$ & China & $\begin{array}{l}\text { Russian } \\
\text { federation }\end{array}$ & Brazil \\
\hline 2005 & 21.6 & 3.4 & 7.1 & 2.5 & 6.5 \\
\hline 2006 & 19.6 & 3.5 & 6.1 & 2.5 & 6.2 \\
\hline 2007 & 17.5 & 3.6 & 5 & 2.5 & 5.6 \\
\hline 2008 & 16.6 & 3.6 & 4 & 2.5 & 5.1 \\
\hline 2009 & 16.3 & 3.6 & 2.8 & 2.5 & 4.4 \\
\hline 2010 & 16 & 3.6 & 2.5 & 2.5 & 3.9 \\
\hline 2011 & 15.6 & 3.7 & 2.5 & 2.5 & 3.4 \\
\hline 2012 & 15 & 4 & 2.5 & 2.5 & 3.1 \\
\hline 2013 & 15.1 & 4.3 & 2.5 & 2.5 & 2.8 \\
\hline 2014 & 14.9 & 4.8 & 2.5 & 2.5 & 2.6 \\
\hline 2015 & 14.7 & 5.2 & 2.5 & 2.5 & 2.5 \\
\hline 2016 & 14.2 & 5.4 & 2.5 & 2.5 & 2.5 \\
\hline 2017 & 13.8 & 5.5 & 2.5 & 2.5 & 2.5 \\
\hline 2018 & 14 & 5.5 & 2.5 & 2.5 & 2.5 \\
\hline 2019 & 15.3 & 6.5 & 2.5 & 2.5 & 2.5 \\
\hline
\end{tabular}

Source: Food and Agriculture Organization (http://www.fao.org/faostat/en/\#home). (Author's compilation)

The data from table 6 reflects that percentage of undernourished populationv has increased in South Africa in 2019 in comparison to 2005, whereas in rest of the BRICS nations it declined. But still India has a very high percentage of undernourished population in comparison to all other BRICS nations (fig.6). In China and Brazil, the percentage of undernourished population has gone down in 2019 in comparison to 2005 whereas it is stagnant in Russia.

Figure 6: Prevalence of undernourishment (\% of population) in BRICS nations

30

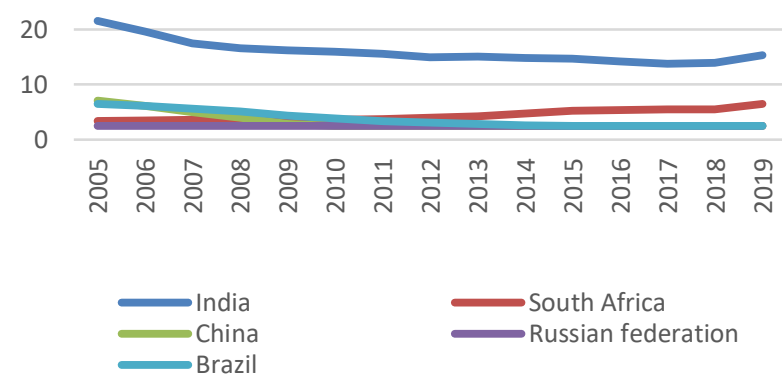

Table 7: Prevalence of anaemia among pregnant women (\%)

\begin{tabular}{|l|l|l|l|l|l|}
\hline & India & $\begin{array}{l}\text { South } \\
\text { Africa }\end{array}$ & China & $\begin{array}{l}\text { Russian } \\
\text { federation }\end{array}$ & $\begin{array}{l}\text { Brazi } \\
\text { l }\end{array}$ \\
\hline 2005 & 53 & 32 & 24.4 & 25.2 & 24.9 \\
\hline 2006 & 52.8 & 31.5 & 23.5 & 24.9 & 24.5 \\
\hline 2007 & 52.6 & 30.9 & 22.6 & 24.6 & 23.9 \\
\hline 2008 & 52.4 & 30.4 & 21.8 & 24.2 & 23.3 \\
\hline 2009 & 52.1 & 29.9 & 21 & 23.8 & 22.6 \\
\hline 2010 & 51.9 & 29.7 & 20.2 & 23.5 & 21.9 \\
\hline 2011 & 51.7 & 29.5 & 19.7 & 23.3 & 21.3 \\
\hline 2012 & 51.4 & 29.4 & 19.3 & 23.2 & 20.8 \\
\hline 2013 & 51.2 & 29.5 & 19.1 & 23.1 & 20.3 \\
\hline 2014 & 50.9 & 29.7 & 18.9 & 23 & 19.9 \\
\hline 2015 & 50.6 & 29.9 & 18.9 & 23 & 19.6 \\
\hline 2016 & 50.4 & 30.1 & 19 & 23.1 & 19.4 \\
\hline 2017 & 50.4 & 30.3 & 18.8 & 23.2 & 19.3 \\
\hline 2018 & 50.2 & 30.5 & 18.6 & 23.3 & 19.2 \\
\hline 2019 & 50.1 & 30.8 & 18.5 & 23.4 & 19.1 \\
\hline
\end{tabular}

Source: World Health Organization, Global Health Observatory Data Repository/World Health Statistics. (Author's compilation)

The data in the table 7 shows percentage of prevalence of anaemiavi among pregnant women. It is very high in almost all the nations of BRICS. Worst country amongst all the BRICS nation is India where 50\% pregnant women are still anaemic in 2019, which was 53\% in 2005. In all other countries the trend is declining but the fastest decline is achieved in Brazil and China (fig.7).

Figure 7: Prevalence of anemia among pregnant women (\%) in BRICS nations

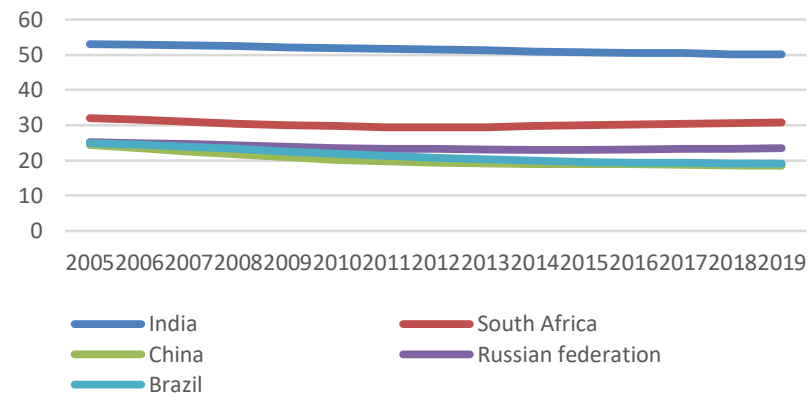

Table 8: Prevalence of anaemia among children (\% of children ages 6-59 months)

\begin{tabular}{|l|l|l|l|l|l|}
\hline & India & $\begin{array}{l}\text { South } \\
\text { Africa }\end{array}$ & China & $\begin{array}{l}\text { Russian } \\
\text { federation }\end{array}$ & Brazil \\
\hline 2005 & 64.4 & 40.8 & 22.6 & 26.5 & 22.2 \\
\hline 2006 & 63.4 & 40.9 & 21.7 & 25.7 & 21.4 \\
\hline 2007 & 62.5 & 40.1 & 20.8 & 25 & 20.6 \\
\hline 2008 & 61.5 & 38.9 & 20.1 & 24.4 & 19.7 \\
\hline 2009 & 60.6 & 37.2 & 19.5 & 23.8 & 18.7 \\
\hline 2010 & 59.7 & 35.6 & 19 & 23.4 & 17.7 \\
\hline 2011 & 58.8 & 34.6 & 18.6 & 23.1 & 16.7 \\
\hline 2012 & 58 & 34.5 & 18.3 & 23 & 15.9 \\
\hline 2013 & 57.2 & 35.3 & 18.2 & 22.7 & 15.1 \\
\hline 2014 & 56.4 & 36.6 & 18.1 & 22.5 & 14.3 \\
\hline 2015 & 55.7 & 38 & 18.2 & 22.2 & 13.7 \\
\hline 2016 & 55 & 39.6 & 18.3 & 22 & 13 \\
\hline 2017 & 54.5 & 41.2 & 18.4 & 21.8 & 12.5 \\
\hline 2018 & 53.9 & 42.9 & 18.5 & 21.8 & 11.9 \\
\hline 2019 & 53.4 & 44.4 & 18.8 & 21.9 & 11.6 \\
\hline
\end{tabular}


Source: World Health Organization, Global Health Observatory Data Repository/World Health Statistics. (Author's compilation)

The percentage of prevalence of anaemia among childrenvii of the ages 6-59 months is presented in table 8. It is very high in almost all the nations of BRICS. Worst country amongst all the BRICS nation is India where $53.4 \%$ pregnant women are still anaemic in 2019, which was $64.4 \%$ in 2005. Except South Africa where it has increased in 2019 in comparison to 2005 in all other countries it has declined in 2019. The fastest decline is achieved in Brazil.

Figure 8: Prevalence of anemia among children (\% of children ages 6-59 months) in BRICS nations

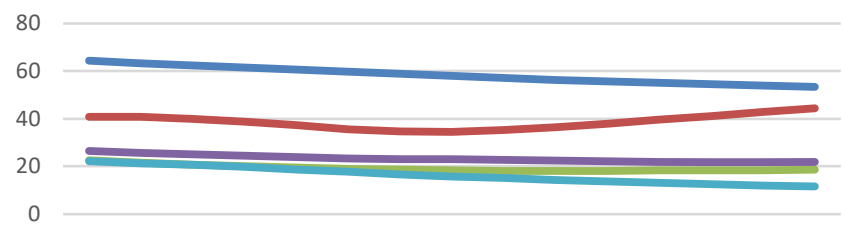

200520062007200820092010201120122013201420152016201720182019

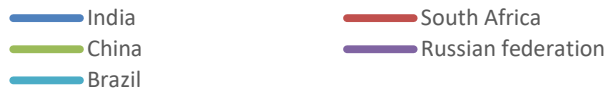

Table 9: Prevalence of anaemia among women of reproductive age (\% of women ages $15-49$ )

\begin{tabular}{|l|l|l|l|l|l|}
\hline Year & India & $\begin{array}{l}\text { South } \\
\text { Africa }\end{array}$ & China & $\begin{array}{l}\text { Russian } \\
\text { federation }\end{array}$ & Brazil \\
\hline 2005 & 54.2 & 32.4 & 18.3 & 21.3 & 24.2 \\
\hline 2006 & 54.1 & 31.7 & 17.6 & 21.1 & 23.6 \\
\hline 2007 & 54.1 & 30.9 & 16.9 & 20.9 & 22.8 \\
\hline 2008 & 54 & 30.2 & 16.4 & 20.7 & 22 \\
\hline 2009 & 53.7 & 29.6 & 15.8 & 20.4 & 20.9 \\
\hline 2010 & 53.5 & 29.1 & 15.3 & 20.2 & 19.9 \\
\hline 2011 & 53.4 & 28.7 & 15 & 20.1 & 19.1 \\
\hline 2012 & 53.2 & 28.6 & 14.8 & 20 & 18.3 \\
\hline 2013 & 53 & 28.6 & 14.8 & 20 & 17.7 \\
\hline 2014 & 52.9 & 28.7 & 14.8 & 20.1 & 17.2 \\
\hline 2015 & 52.7 & 28.9 & 14.9 & 20.1 & 16.8 \\
\hline 2016 & 52.6 & 29.1 & 15.1 & 20.3 & 16.5 \\
\hline 2017 & 52.8 & 29.5 & 15.2 & 20.6 & 16.3 \\
\hline 2018 & 52.9 & 29.9 & 15.3 & 20.8 & 16.2 \\
\hline 2019 & 53 & 30.5 & 15.5 & 21.1 & 16.1 \\
\hline
\end{tabular}

Source: World Health Organization, Global Health Observatory Data Repository/World Health Statistics. (Author's compilation)

Table 9 shows percentage of prevalence of anaemia among women of reproductive agesviii 15-49. It is quite high in almost all the nations of BRICS. Worst country amongst all the BRICS nation is India where 53\% women of reproductive age are still anaemic in 2019, which was $54.2 \%$ in 2005 . No doubt it is declining in all the BRICS countries but the fastest decline is in Brazil. This is due to long visionary power of the new government of Brazil.

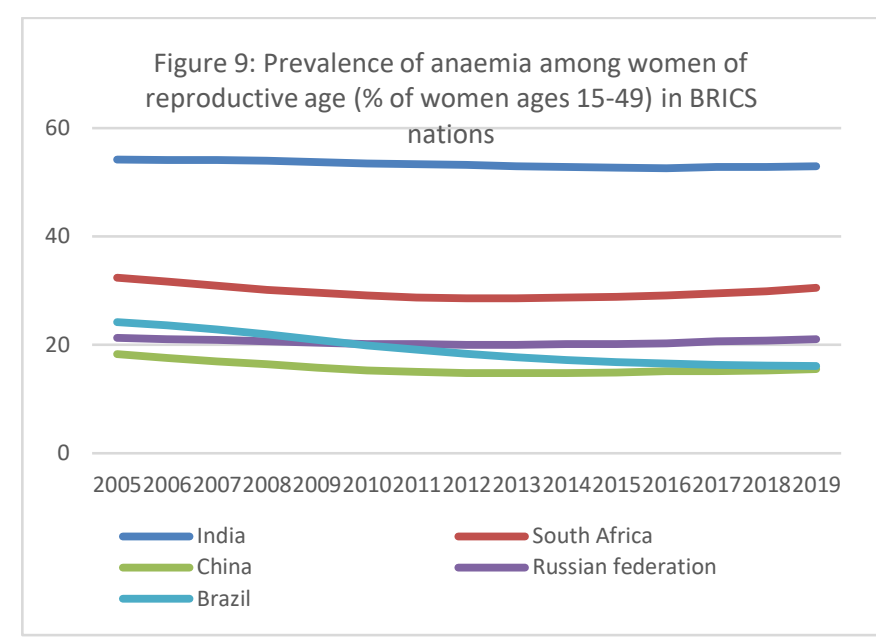

Table 10: Prevalence of anaemia among non-pregnant women (\% of women ages 15-49)

\begin{tabular}{|l|l|l|l|l|l|}
\hline Year & $\begin{array}{l}\text { Indi } \\
\text { a }\end{array}$ & $\begin{array}{l}\text { South } \\
\text { Africa }\end{array}$ & $\begin{array}{l}\text { Chin } \\
\text { a }\end{array}$ & $\begin{array}{l}\text { Russian } \\
\text { federation }\end{array}$ & $\begin{array}{l}\text { Brazi } \\
\text { l }\end{array}$ \\
\hline 2005 & 54.2 & 32.4 & 18.1 & 21.2 & 24.2 \\
\hline 2006 & 54.2 & 31.7 & 17.4 & 21 & 23.6 \\
\hline 2007 & 54.2 & 30.9 & 16.7 & 20.8 & 22.8 \\
\hline 2008 & 54.1 & 30.2 & 16.2 & 20.6 & 21.9 \\
\hline 2009 & 53.8 & 29.5 & 15.6 & 20.3 & 20.9 \\
\hline 2010 & 53.6 & 29 & 15.1 & 20.1 & 19.8 \\
\hline 2011 & 53.5 & 28.7 & 14.8 & 20 & 19 \\
\hline 2012 & 53.3 & 28.5 & 14.7 & 19.9 & 18.3 \\
\hline 2013 & 53.1 & 28.5 & 14.7 & 19.9 & 17.6 \\
\hline 2014 & 53 & 28.6 & 14.6 & 20 & 17.1 \\
\hline 2015 & 52.8 & 28.8 & 14.8 & 20 & 16.7 \\
\hline 2016 & 52.8 & 29.1 & 15 & 20.2 & 16.4 \\
\hline 2017 & 52.9 & 29.4 & 15.1 & 20.5 & 16.2 \\
\hline 2018 & 53 & 29.9 & 15.2 & 20.8 & 16.1 \\
\hline 2019 & 53.1 & 30.5 & 15.4 & 21.1 & 16 \\
\hline
\end{tabular}

Source: World Health Organization, Global Health Observatory Data Repository/World Health Statistics. (Author's compilation)

The data from table 10 shows percentage of prevalence of anaemia among non-pregnant womenix of ages 1549. It is quite high in almost all the nations of BRICS. Worst country amongst all the BRICS nation is India where $53.1 \%$ non-pregnant women are still anaemic in 2019 , which was $54.2 \%$ in 2005 . No doubt it is declining in all the BRICS countries but the fastest decline is in Brazil (fig.10).

Figure 10: Prevalence of anaemia among nonpregnant women (\% of women ages 15-49) in BRICS nations

60

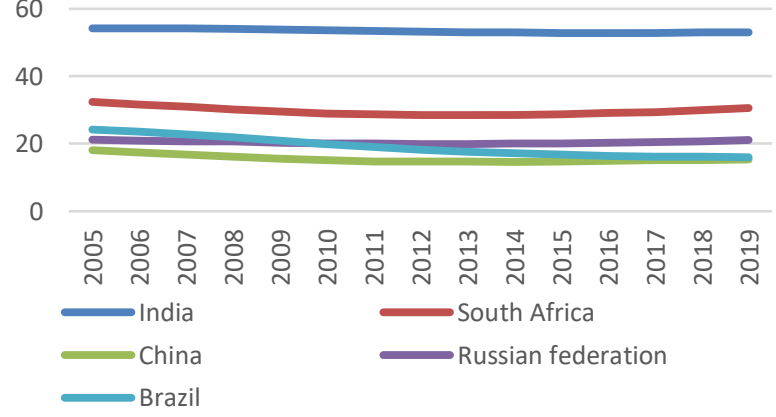


Table 11: Prevalence of overweight (modelled estimate, $\%$ of children under 5 )

\begin{tabular}{|l|l|l|l|l|l|}
\hline Year & India & $\begin{array}{l}\text { South } \\
\text { Africa }\end{array}$ & China & Brazil & $\begin{array}{l}\text { Russian } \\
\text { federation }\end{array}$ \\
\hline 2005 & 3 & 12 & 6.6 & 6.5 &.. \\
\hline 2006 & 3 & 12.2 & 6.7 & 6.5 &.. \\
\hline 2007 & 2.9 & 12.3 & 6.8 & 6.6 &.. \\
\hline 2008 & 2.8 & 12.5 & 6.9 & 6.6 &.. \\
\hline 2009 & 2.7 & 12.6 & 6.9 & 6.7 &.. \\
\hline 2010 & 2.6 & 12.6 & 7 & 6.8 &.. \\
\hline 2011 & 2.5 & 12.7 & 7.1 & 6.8 &.. \\
\hline 2012 & 2.4 & 12.8 & 7.2 & 6.9 &.. \\
\hline 2013 & 2.3 & 12.8 & 7.3 & 6.9 &.. \\
\hline 2014 & 2.2 & 12.9 & 7.4 & 7 &.. \\
\hline 2015 & 2.1 & 12.9 & 7.5 & 7.1 &.. \\
\hline 2016 & 2.1 & 12.9 & 7.5 & 7.1 &.. \\
\hline 2017 & 2 & 12.9 & 7.7 & 7.1 &.. \\
\hline 2018 & 2 & 12.9 & 7.9 & 7.2 &.. \\
\hline 2019 & 1.9 & 12.9 & 8.1 & 7.2 &.. \\
\hline 2020 & 1.9 & 12.9 & 8.3 & 7.3 &.. \\
\hline
\end{tabular}

Source: UNICEF, WHO, World Bank: Joint child malnutrition estimates (JME). (Author's compilation)

Table 11 represents percentage of prevalence of overweight children under $5 x$ in BRICS nations. In this context with the lowest percentage since 2005 till 2020 India is in the best position in comparison to all other nations (fig.11). The country is exhibiting the declining trend as well. In China and Brazil, the trend is increasing whereas in South Africa it is almost stagnant from 2005 till 2020. Data is not available of Russia.

Figure 11: Prevalence of overweight (modelled estimate, $\%$ of children under 5 ) in BRICS nations

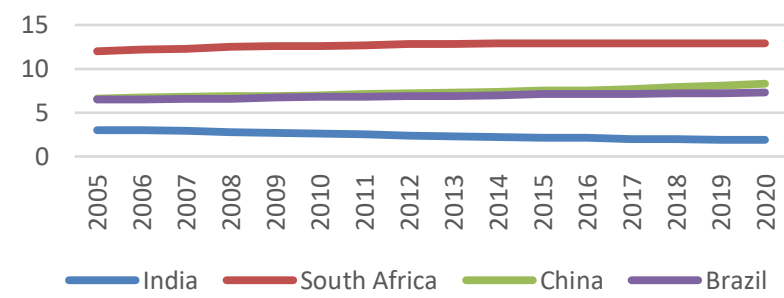

Table 12: Prevalence of stunting, height for age (modelled estimate, \% of children under 5)

\begin{tabular}{|l|l|l|l|l|l|}
\hline Year & India & $\begin{array}{l}\text { South } \\
\text { Africa }\end{array}$ & China & Brazil & $\begin{array}{l}\text { Russian } \\
\text { federation }\end{array}$ \\
\hline 2005 & 48.2 & 27.6 & 13 & 7.5 &.. \\
\hline 2006 & 47.8 & 27 & 12 & 7.3 &.. \\
\hline 2007 & 47.3 & 26.2 & 11.1 & 7.1 &.. \\
\hline 2008 & 46.6 & 25.4 & 10.3 & 6.9 &.. \\
\hline 2009 & 45.7 & 24.7 & 9.5 & 6.7 &.. \\
\hline 2010 & 44.5 & 24.1 & 8.7 & 6.6 &.. \\
\hline 2011 & 43.1 & 23.8 & 8 & 6.4 &.. \\
\hline 2012 & 41.7 & 23.6 & 7.4 & 6.3 &.. \\
\hline 2013 & 40.3 & 23.4 & 6.9 & 6.2 &.. \\
\hline 2014 & 38.9 & 23.3 & 6.4 & 6.1 &.. \\
\hline 2015 & 37.5 & 23.1 & 6.1 & 6.1 &.. \\
\hline 2016 & 36.2 & 23 & 5.9 & 6.1 &.. \\
\hline 2017 & 34.8 & 22.9 & 5.5 & 6.1 &.. \\
\hline 2018 & 33.5 & 23 & 5.2 & 6.1 &.. \\
\hline 2019 & 32.1 & 23.1 & 4.9 & 6.1 &.. \\
\hline 2020 & 30.9 & 23.2 & 4.7 & 6.1 &.. \\
\hline
\end{tabular}

Source: UNICEF, WHO, World Bank: Joint child malnutrition estimates (JME). (Author's compilation)

The percentage of prevalence of stunting, height for age of children under 5xi in BRICS nations is presented in table 12. In this context with the highest percentage since 2005 till 2020 India is in the worst position in comparison to all other nations. Although the country has exhibited declining trend but still it is highest among all the BRICS nations. In South Africa as well the problem of stunting among below 5-year-old children is quite high. It is lowest in China in 2020 and constant in Brazil since 2014 till 2020. Data is not available for Russia.

Figure 12: Prevalence of stunting, height for age (modelled estimate, \% of children under 5 ) in BRICS nations

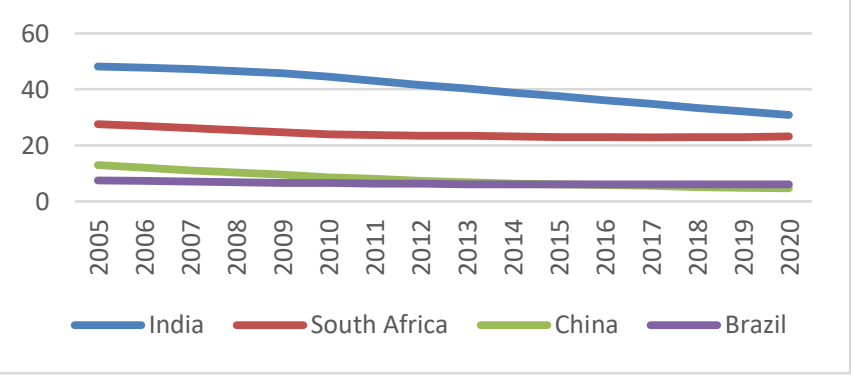

\section{FINDINGS}

The lowest current health expenditure in India amongst all the BRICS nations is a matter of great concern. Even after three decades of economic liberalisation health sector looks neglected due to stagnancy in the current health expenditure. It has increased the misery of poor people as their out-of-pocket expenditure is increasing day by day to avail health services. The low current health expenditure and high out of pocket expenditure is bringing inequity in the access of health services. Where rich sections are able to afford five-star health services poorer are deprived of even from availing essential health services. Poor people are getting doubly affected due to poor affordability and accessibility of health services. This problem is grimmer in rural areas. In terms of availability of beds in the hospital China's throughout increasing trend has reflected the long vision of the country to keep the health infrastructure ready to meet any unprecedented crisis. Russia has shown a quite volatile trend in terms of number of Physicians in BRICS nations per 1,000 people, whereas Brazil, China, South Africa and India are almost in stagnant position. Availability of nurses, midwives, doctors, medical practitioner medical staffs are all directly related with the patients' health as personal supervision, treatment and testing heightens with it. The state of undernourishment is also directly related to the dietary energy levels that are required to maintain a normal active and healthy life. India needs to take this issue very seriously. In the state of undernourishment demographic dividend of India will prove a disaster which will bring more pressure on health system. The prevalence of overweight and prevalence of stunting, 
height for age among children of below 5 years of age draws our attention towards the unhealthy status as well as paucity of nutrients in daily food consumption of children. The problem of overweight is grimmer in highand-middle income countries of BRICS. The problem related to stunting is highest in India and then South Africa. With the increase in income the consumption basket of household has diversified but this diversification is not accomplished with nutrition. This led to the situation of deprivation specially amongst children as they eat what is served to them. Therefore, parents need to pay attention towards the burgeoning problem of obesity and stunting amongst their children.

\section{SUGGESTIONS and POLICY RECOMMENDATION}

Amongst BRICS nations inequity related to health services are emerging as the greatest challenge which governments of each individual nations need to address urgently. Looking at the high density of people in the case of India, it is important to provide medical services at each and every nook and corner of the country irrespective of developed or underdeveloped status of the region. This measure will need huge government expenditure. Thus, to reduce the pressure of health expenses on people it is essential that Government should increase current expenditure and provide health amenities extensively without delay. All the countries of BRICS jointly act on increasing the health infrastructure. Special attention is needed by the government of India as it is the second most populous country not only amongst BRICS nations but in the world. Each country of BRICS should individually assess the risk associated with poor availability of physicians and should work towards increasing the number by inducting more physicians in the short run. In the long run, opening of more medical colleges, increasing the number of seats and thereby recruiting more doctors will sort out the problem. It will improve health of the people which will ultimately increase the efficiency of the economy and thereafter increase the national income. Collective cooperation and exchange of expertise and specialisation amongst BRICS nations under the commitment of Universal Health Coverage will take the emerging nations towards sustainable health agenda. It is important that all the nations of BRICS should actively work towards it. Poor current health expenditure, lack of medical doctors, nurses and staffs, a smaller number of available beds in the hospital increases the misery of common people which compels them to search for alternatives for example shifting to private hospital which impacts their pockets. All these constraints affect the overall health of the citizens and ultimately the health of the country. Governments of India and South Africa should intensify the provision and distribution of mid-day meals, iron, vitamin and other supplementary pills. Door step mobile services in the distribution of essential food items freely will have quick impact on the people's health of both the countries. Maternal health impacts both mother and the baby in the womb. To improve the health of pregnant women, children of 6-59 months and women of reproductive age active participation of community level health workers, Mini mobile hospitals and pathology laboratories for checkups and testing and distribution of supplementary items, food, medicines, vitamins, pure drinking water will be a move towards right direction. It should be expedited in India at an emergency level as the percentage of all these types of anaemia is very high in the country. Among the non-pregnant women, the percentage can be reduced by spreading the awareness related to food habits, daily routine, importance of including the nutrients in daily consumption. For this mobile apps, putting billboards and educating them at community level can bring changes at speedy rate. Monthly Health monitoring and provision of free nutritious food in the kindergarten level by the administration will definitely prove a step forward towards solving the problem of obesity and stunting in children. Educating parents, children, caretakers of kids will also bring positive changes in reducing the percentage of overweight and stunting among children of under 5 age group. The measures can be taken by government at community, local, state and national levels from supply side as well like approving the food items meant for children by examining the nutrient value of each component used in the process of production. Organising health related activities like yoga and facilitating parks, indoor and outdoor sports will also help in bringing remarkable changes in the direction of controlling obesity and stunting amongst children. Joint cooperation by BRICS nations under the universal Health Coverage specially targeting the children can bring remarkable improvement in it.

\section{CONCLUSION}

Buss, P. M., Ferreira, J. R., \& Hoirisch, C. (2014) opine that there is the need and the opportunity for joint action of the BRICS in terms of the "diplomacy of health" reinforcing the whole process of sustainable development. Kulkarni, L. (2016) believe that heath outcome in BRICS nations will not improve without improving the quality of delivery and finance system. Jakovljevic, M., (2019) find that BRICS nations have a great potential for embracing a public health agenda aimed at promoting physical activity and healthy lifestyles as part of the BRICS public health policies in order to improve population health and reduce the burden of noncommunicable diseases. Thus, it is important that BRICS nations should have a Mutual cooperation on medical and allied products and assistance on tariff related matters to sort out the problems arising from trade related to health equipment and services. Furthermore, it is essential to mobilize finance to tackle emergent health related challenges in member nations. Joint cooperation on encouraging indigenous production of medical equipment and then facilitation of these equipment by exporting it amongst the member countries and to other countries on international level should be the top most priority of BRICS nations. Another much needed cooperation is on 
digital front. BRICS countries should come forward to promote digital platforms for solving health related issues in member countries. It will bring many areas related to health on one platform where expertise in the specific area of each country will certainly benefit the other. The areas can extend up to use of traditional medicines, Ayurveda, herbs, home remedies, yoga, wellness methods, professional consultation and many more.

\section{REFERENCES}

Awe, O. O., Dogbey, D. M., Sewpaul, R., Sekgala, D., \& Dukhi, N. (2021). Anaemia in Children and Adolescents: A Bibliometric Analysis of BRICS Countries (19902020). International Journal of Environmental Research and Public Health, 18(11), 5756.

Buss, P. M., Ferreira, J. R., \& Hoirisch, C. (2014). Health and development in BRICS countries. Saúde e Sociedade, 23, 390-403.

Food and Agriculture Organization (http://www.fao.org/faostat/en/\#home).

Hisham, S., Dsouza, B. C., Rasheed, S. A., Kamath, R., \& Mishra, A. V. (2018). Assessment of Healthcare Systems Across BRICS Nations, What India Can Learn from the Rest?. Journal of Clinical \& Diagnostic Research, 12(12).

Jakovljevic, M., Potapchik, E., Popovich, L., Barik, D., \& Getzen, T. E. (2017). Evolving health expenditure landscape of the BRICS nations and projections to 2025. Health economics, 26(7), 844-852.

Jakovljevic, M., Timofeyev, Y., Ekkert, N. V., Fedorova, J. V., Skvirskaya, G., Bolevich, S., \& Reshetnikov, V. A. (2019). The impact of health expenditures on public health in BRICS nations. Journal of sport and health science, 8(6), 516.

Kulkarni, L. (2016). Health inputs, health outcomes and public health expenditure: evidence from the BRICS countries. International Journal of Applied Economics, 31(1), 72-84.

\footnotetext{
${ }^{\mathrm{i}}$ Share of out-of-pocket payments of total current health expenditures. Out-of-pocket payments are spending on health directly out-of-pocket by households.

${ }^{i i}$ Hospital beds include inpatient beds available in public, private, general, and specialized hospitals and rehabilitation centres. In most cases beds for both acute and chronic care are included.

iii Physicians include generalist and specialist medical practitioners.

${ }^{\text {iv }}$ Nurses and midwives include professional nurses, professional midwives, auxiliary nurses, auxiliary midwives, enrolled nurses, enrolled midwives and other associated personnel, such as dental nurses and primary care nurses.

${ }^{v}$ Prevalence of undernourishment is the percentage of the population whose habitual food consumption is insufficient to provide the dietary energy levels that are required to maintain a normal active and healthy life. Data showing as 2.5 may signify a prevalence of undernourishment below $2.5 \%$.

${ }^{\mathrm{vi}}$ Prevalence of anaemia, pregnant women, is the percentage of pregnant women whose haemoglobin level is less than 110 grams per litre at sea level.

vii Prevalence of anaemia, children ages 6-59 months, is the percentage of children ages 6-59 months whose haemoglobin level is less than 110 grams per litter, adjusted for altitude.
}

Larionova, M., Rakhmangulov, M., Sakharov, A., \& Shelepov, A. (2014). BRICS: Emergence of health agenda. International Organisations Research Journal (IORJ) Vol, 9.

Marten, R., McIntyre, D., Travassos, C., Shishkin, S., Longde, W., Reddy, S., \& Vega, J. (2014). An assessment of progress towards universal health coverage in Brazil, Russia, India, China, and South Africa (BRICS). The Lancet, 384(9960), 2164-2171.

Mohan, M. R., \& Jayaraman, K. (2019). A Comparative Study of India and Brics Nations' Public Health Care with A special reference to India's Position. GIS Business, 14(6), 565-576.

Rao, K. D., Petrosyan, V., Araujo, E. C., \& McIntyre, D. (2014). Progress towards universal health coverage in BRICS: translating economic growth into better health. Bulletin of the World Health Organization, 92, 429-435.

Romaniuk, P., Poznańska, A., Brukało, K., \& Holecki, T. (2020). Health system outcomes in BRICS countries and their association with the economic context. Frontiers in public health, 8,80 .

Silva Junior, J. B. D., Desiraju, K., Matsoso, P., Minghui, R., \& Salagay, O. (2014). BRICS cooperation in strategic health projects.

Tediosi, F., Finch, A., Procacci, C., Marten, R., \& Missoni, E. (2016). BRICS countries and the global movement for universal health coverage. Health policy and planning, 31(6), 717-728.

UNICEF, WHO, World Bank: Joint child malnutrition estimates (JME).

World Health Organization Global Health Expenditure database (http://apps.who.int/nha/database).

World Health Organization, Global Health Observatory Data Repository/World Health Statistics.

World Health Organization's Global Health Workforce Statistics, OECD, supplemented by country data.

Yadav, M. (2020). Out-of-pocket expenditure and its relationship with several human development indicators: a case study of brics nations. Editorial board, 9(4), 188.

\footnotetext{
viii Prevalence of anaemia among women of reproductive age refers to the combined prevalence of both non-pregnant with haemoglobin levels below $12 \mathrm{~g} / \mathrm{dL}$ and pregnant women with haemoglobin levels below 11 $\mathrm{g} / \mathrm{dL}$.

${ }^{\text {ix }}$ Prevalence of anaemia, non-pregnant women, is the percentage of nonpregnant women whose haemoglobin level is less than 120 grams per litter at sea level.

${ }^{x}$ Prevalence of overweight children is the percentage of children under age 5 whose weight for height is more than two standard deviations above the median for the international reference population of the corresponding age as established by the WHO's new child growth standards released in 2006.

${ }^{x i}$ Prevalence of stunting is the percentage of children under age 5 whose height for age is more than two standard deviations below the median for the international reference population ages 0-59 months. For children up to two years old height is measured by recumbent length. For older children height is measured by stature while standing. The data are based on the WHO's new child growth standards released in 2006.
} 